Article

\title{
Can MRI Biomarkers Predict Triple-Negative Breast Cancer?
}

\author{
Giuliana Moffa *DiD, Francesca Galati ${ }^{D}$, Emmanuel Collalunga, Veronica Rizzo (D), Endi Kripa, \\ Giulia D'Amati (D) and Federica Pediconi
}

Department of Radiological, Oncological and Pathological Sciences, Sapienza-University of Rome, 00161 Rome, Italy; francesca.galati@uniroma1.it (F.G.); e.collalunga@libero.it (E.C.); veronica.rizzo0388@gmail.com (V.R.); endi.kripa@uniroma1.it (E.K.); giulia.damati@uniroma1.it (G.D.); federica.pediconi@uniroma1.it (F.P.)

* Correspondence: moffa.giuliana@gmail.com; Tel.: +39-06-4455602; Fax: +39-06-490243

Received: 28 November 2020; Accepted: 13 December 2020; Published: 15 December 2020

\begin{abstract}
The purpose of this study was to investigate MRI features of triple-negative breast cancer (TNBC) compared with non-TNBC, to predict histopathological results. In the study, 26 patients with TNBC and 24 with non-TNBC who underwent multiparametric MRI of the breast on a 3 T magnet over a 10-months period were retrospectively recruited. MR imaging sets were evaluated by two experienced breast radiologists in consensus and classified according to the 2013 American College of Radiology (ACR) BI-RADS lexicon. The comparison between the two groups was performed using the Chi-square test and followed by logistic regression analyses. We found that $92 \%$ of tumors presented as mass enhancements $(p=0.192) .41 .7 \%$ of TNBC and $86.4 \%$ of non-TNBC had irregular shape ( $p=0.005) ; 58.3 \%$ of TNBC showed circumscribed margins, compared to $9.1 \%$ of non-TNBC masses $(p=0.001) ; 75 \%$ of TNBC and $9.1 \%$ of non-TNBC showed rim enhancement $(p<0.001)$. Intralesional necrosis was significantly associated with $\operatorname{TNBC}(p=0.016)$. Rim enhancement and intralesional necrosis risulted to be positive predictors at univariate analysis ( $\mathrm{OR}=29.86$, and 8.10 , respectively) and the multivariate analysis confirmed that rim enhancement is independently associated with TNBC $(\mathrm{OR}=33.08)$. The mean ADC values were significantly higher for TNBC $(p=0.011)$. In conclusion, TNBC is associated with specific MRI features that can be possible predictors of pathological results, with a consequent prognostic value.
\end{abstract}

Keywords: triple-negative breast cancer; 3 T MRI; DWI; breast cancer prognostic factors

\section{Introduction}

Breast cancer is a heterogeneous disease with different morphologic features, clinical course and response to treatment. As a consequence, personalized management is required [1,2]. In addition to traditional parameters, such as tumor size, histological grade and lymph node status, molecular markers have been introduced into the patient's care routine [3]. At present, surrogate definitions of breast cancer subtypes are based on immunohistochemical measurements of the expression of estrogen receptor (ER), progesterone receptor (PgR), human epidermal growth factor receptor 2 (HER2), with in situ hybridization confirmation where appropriate, and on the assessment of the proliferation index. According to immunohistochemistry, five clinico-pathologic breast cancer subtypes were identified: luminal A-like, luminal B-like HER2 negative, luminal B-like HER2 positive, HER2 positive, and triple-negative [4].

Triple-negative breast cancer (TNBC), characterized by ER, PgR and HER2 negativity, is commonly used as a surrogate for intrinsic basal-like subtype and accounts for $10-20 \%$ of invasive breast cancers [5]. TNBC is a biologically and clinically aggressive tumor (with an increased rate of local recurrence and distant metastases, compared to other breast cancer subtypes [5]), characterized by early onset 
(usually <50-year old women) and frequent association with BRCA 1 mutation [5,6]. In spite of the aggressiveness, TNBC can mimic benign lesions at conventional breast imaging, lacking the typical malignant features of cancer. On mammography, TNBC usually presents as a mass, with circumscribed margins ( $8-43 \%$ of cases) and without associated calcifications $(89-100 \%$ of cases) $[7,8]$. On ultrasound examination (US), TNBC often appears as a regular-shaped mass with well-circumscribed margins (21-27\% [8]), parallel orientation and posterior acoustic enhancement (24-41\% [8]) [9]. For what concerns multiparametric magnetic resonance imaging (MP-MRI), previously published papers have described the most typical features of TNBC that comprised mass-shaped lesions, rim enhancement, and intra-tumoral hyperintensity at T2-weighted sequences [7,10-13]. Moreover, preliminary researches have demonstrated that TNBC is more likely to have a higher apparent diffusion coefficient (ADC) value on diffusion-weighted imaging (DWI) than other breast cancer subtypes [14,15].

In the precision medicine era, it seems particularly important for every breast radiologist to suspect and ultimately non-invasively predict histological results of TNBC, considering the particularly aggressive behavior of this diagnostic misleading subtype. As far as the authors know, there are few studies in literature that investigated the differences between MRI features of TNBC and non-TNBC and were conducted mostly on $1.5 \mathrm{~T}$ scanners, not including functional techniques, such as DWI $[10,14,16-21]$. Therefore, the aim of this study was to investigate MRI features of TNBC compared with non-TNBC on a $3 \mathrm{~T}$ scanner, to increase existing knowledge about TNBC, including elements of radiological-pahological correlation.

\section{Materials and Methods}

\subsection{Study Population}

The study was conducted according to Good Clinical Practice guidelines and obtained the approval of our institutional review board (\#0525032019, approved 25 March 2019). The requirement for informed consent was waived because of the retrospective nature of the study.

From April 2017 to January 2018, 162 patients with newly diagnosed biopsy-proven breast cancer who underwent MP-MRI of the breast at the time of diagnosis were included in this study.

Core needle biopsies (CNB) were performed under US guidance by two experienced breast interventional radiologist using a $12 \mathrm{MHz}$ linear probe (Affiniti $70 \mathrm{G}$; Philips, Amsterdam, Netherlands) and a 14-gauge semi-automatic biopsy needle (Precisa; HS Hospital Service SpA, Aprilia, Italy).

Exclusion criteria included; the inability to complete MRI examination ( $\mathrm{n}=5)$; previous history of breast cancer or recurrent disease $(n=21)$; ongoing neoadjuvant chemotherapy (NACT) or other cancer treatments $(n=16)$; presence of breast implants $(n=18)$; CNB performed less than 14 days before MRI, to eliminate possible bias due to the diagnostic procedure such as the presence of a voluminous post-biopsy hematoma $(n=15)$; complete histological data not available $(n=10)$.

Out of the remaining 77 patients, 26 with histological diagnosis of TNBC were used for the evaluation. The group included women aged between 35 and 60 years, affected by invasive breast carcinoma. A control group, composed of a similar number of patients of the same age with histologically proven non-TNBC and who underwent breast MP-MRI during the same period, was randomly included $(n=24)$. Clinical data were obtained from medical records. Patient data was collected using Excel 2011 (Microsoft Corporation, Redmont, WA, USA).

\subsection{MRI Technique}

All breast MRI examinations were performed on a 3 T magnet (Discovery MR 750; GE Healthcare, Chicago, IL, USA) with a dedicated 8-channel breast coil compatible with parallel imaging, and patients in a prone position. Breast MRI protocol included: axial pre-contrast 2D FSE T2-weighted fat-suppressed sequence (repetition time $[R T]=9000-11,000 \mathrm{~ms}$, echo time [ET] 119-120 ms, matrix $=512 \times 224$, slice thickness $=3-5 \mathrm{~mm}$, field of view $[\mathrm{FOV}]=35 \times 35 \mathrm{~cm}, \mathrm{NEX}=1$, scan time $=130 \mathrm{~s}$ ), axial pre-contrast diffusion-weighted echo-planar imaging (DWI-EPI) sequence (RT $=4983-5314 \mathrm{~ms}$, 
$\mathrm{ET}=58 \mathrm{~ms}$, matrix $=150 \times 150$, slice thickness $=3-5 \mathrm{~mm}, \mathrm{FOV}=350 \times 350 \mathrm{~mm}, \mathrm{NEX}=2-2-4$, scan time $=230 \mathrm{~s}$ ), axial dynamic three-dimensional (3D) spoiled gradient-echo T1-weighted fat-suppressed sequences (flip angle $=15^{\circ}, \mathrm{RT}=8 \mathrm{~ms}$, ET $=4 \mathrm{~ms}$, matrix $=512 \times 256$, slice thickness $=1.40 \mathrm{~mm}, \mathrm{FOV}=380 \times 380 \mathrm{~mm}, \mathrm{NEX}=1)$ and sagittal 3D spoiled gradient-echo post-contrast T1-weighted sequence.

Fat suppression of T2-weighted sequences was based on a three-point Dixon technique (IDEAL). DWI-EPI sequences comprised b-values of 0,500 and $1000 \mathrm{~s} / \mathrm{mm}^{2}$ and the corresponding apparent diffusion coefficient (ADC) maps were calculated automatically. Axial dynamic 3D T1-weighted fat-suppressed sequences (VIBRANT) were performed before and four times after contrast agent administration (total acquisition time of $120 \mathrm{~s}$ ). Post-contrast T1-weighted images were acquired after the administration of $0.1 \mathrm{mmol} / \mathrm{kg}(0.2 \mathrm{~mL} / \mathrm{kg})$ gadolinium-based contrast agent (Gadoteridol—Prohance $279.3 \mathrm{mg} / \mathrm{mL}$; Bracco Imaging Italia S.r.l., Milano, Italy) at a rate of 2 or $3 \mathrm{~mL} / \mathrm{s}$. Gadoteridol was power-injected through a peripheral venous access (22 gauge) and was followed by a 20-mL saline flush. Post-processing subtraction images were obtained for all examinations.

Imaging of premenopausal women was performed between the 7th and the 14th day of the menstrual cycle, according to current guidelines [22].

\subsection{MR Imaging Evaluation}

MRI images evaluation was performed retrospectively by two experienced breast radiologists, with 15 and 7 years of experience, respectively. The readers, blinded to clinical and histopathological information, evaluated all the MR imaging sets in consensus at the system console, using the automated software available. The evaluation was performed using all images available and classified according to the 2013 American College of Radiology (ACR) Breast Imaging Reporting and Data System (BI-RADS) lexicon [23]. All the lesions were measured and size in $\mathrm{mm}$ was reported. The presence of intralesional necrosis and perilesional edema was assessed visually on pre-contrast fat-suppressed T2-weighted images as areas of high signal intensity (as high as that of water) localized within the lesion, and around or posteriorly to the lesion, respectively. Moreover, T2-weighted signal intensity of each lesion was evaluated visually and classified as hypointense (when lower than surrounding glandular tissue), isointense (same intensity as glandular tissue), and hyperintense (when higher than glandular tissue) on the basis of the predominant signal intensity of the lesion. Hyperintense regions were qualitatively evaluated on high $b$-value images $\left(b=1000 \mathrm{~s} / \mathrm{mm}^{2}\right)$. ADC values of lesions were obtained drawing manually a two-dimensional (2D) region of interest in the center of the area of restricted diffusion on ADC maps.

The presence of possible axillary lymphadenopathies (characterized by: size $>1 \mathrm{~cm}$, round shape, loss of the fatty hilum, cortical thickening) was assessed on post-contrast fat-suppressed T1-weighted sequences.

\subsection{Histopathological Analysis}

All the specimens were evaluated according to standardized protocols by a pathologist with more than 20 years of experience. The specimens were fixed in $10 \%$ formalin for 6 to $8 \mathrm{~h}$, then processed to obtain paraffin blocks subsequently cut in $5-\mu \mathrm{m}$-thick slices and stained with hematoxylin-eosin. Tumors were classified following the World Health Organization Classification and graded according to the Nottingham Histologic Score. The immunohistochemical analysis was carried out using mouse monoclonal antibodies anti-estrogen receptor (ER) alpha (6F11; Novocastra Laboratories Ltd., Newcastle upon Tyne, UK) and anti-progesterone receptor (PgR-312; Novocastra Laboratories Ltd., Newcastle upon Tyne, UK). HER2 evaluation was performed using a semiquantitative immunohistochemical assay (HercepTest; Dako Agilent, Santa Clara, CA, USA); the intensity of HER2 membrane staining was scored as $0,1+, 2+$ or $3+$. In case of equivocal result (2+) fluorescence in situ hybridization for HER2 gene amplification was performed, according to the 2013 American Society of Clinical Oncology/College of American Pathologists guidelines [24]. Proliferation index was determined using anti-Ki-67 monoclonal antibody 
MM1 (Novocastra Laboratories Ltd., Newcastle upon Tyne, UK). The Ki-67 value was expressed as the percentage of tumor cells showing nuclear staining. Considering the immunohistochemical features, tumors were classified as luminal A-like, luminal B-like HER2-negative, luminal B-like HER2-positive, HER2-positive, and triple-negative, according to the 2013 St. Gallen Consensus Conference [4].

\subsection{Statistical Analysis}

The Kolmogorov-Smirnov $\mathrm{Z}$ test was performed to assess the normality of the distribution for all the variables tested. Continuous normal variables were expressed as mean \pm standard deviation (SD) while continuous non-normal variables were expressed as median and range. Categorical variables were expressed as percentages. A comparison of categorical variables was performed using the Chi-square test with Yates correction, while the Bonferroni correction was used for post-hoc Chi-square analysis. Univariate and multivariate logistic regression analyses were performed to identify the predicting value of imaging-derived features associated with TNBC. The statistical analyses and the graphs plotting were performed using the MedCalc Software version 8.0 (MedCalc Software, Mariakerke, Belgium).

$p$-values $<0.05$ were considered statistically significant. All $p$-values were calculated using a two-tailed significance level.

\section{Results}

A total of 50 patients were included in this study, 26 affected by TNBC (group 1) and 24 affected by non-TNBC (group 2). Patients' age ranged from 35 to 60 years (mean age $=50.5, \mathrm{SD}=7.2$ ). The mean age at diagnosis was $49.9(\mathrm{SD}=8.1)$ in group 1 , and $50.9(\mathrm{SD}=6.6)$ in group 2 , respectively. No statistical association was found between age and TNCB subtype in our study population $(p=0.839)$.

Median lesion size at MR imaging was $21.5 \mathrm{~mm}$ (range $6-60 \mathrm{~mm}$ ). $57.7 \%$ of TNBCs were $\geq 2 \mathrm{~cm}$, while $42.3 \%$ were smaller. Among non-TNBCs, only $45.8 \%$ measured $\geq 2 \mathrm{~cm}$. No statistical association was found between tumor size and TNBC subtype $(p=0.308)$, even if TNBC were larger than non-TNBC on average.

In the MRI examination most tumors in both groups appeared as mass enhancement: $92.3 \%$ in group 1 (TNBC), and $91.7 \%$ in group 2 (non-TNBC), respectively $(p=0.192)$. Most masses were characterized by irregular shape $(41.7 \%$ of TNBCs, and $86.4 \%$ of non-TNBCs, respectively), with a statistically significant difference in frequency between the two groups $(p=0.005)$. For what concerns margins, TNBC masses showed circumscribed margins in $58.3 \%$ of patients, while non-TNBC masses only in $9.1 \%$ of cases $(p=0.001)$. Internal enhancement characteristics were classified as rim enhancement in 18 patients (75\%) of group 1 (TNBC) and only 2 patients $(9.1 \%)$ of group 2 (non-TNBC). Rim enhancement confirmed to be one MRI feature that is significantly associated with TNBC subtype $(p<0.00001)$ in our study population.

Only 4 patients ( $8 \%$ of the entire study population) showed non-mass enhancements at breast MRI: 2 (7.7\%) with TNBC (1 segmental and 1 regional distribution) and $2(8.3 \%)$ with non-TNBC (2 regional), respectively.

TNBCs showed T2-signal hyperintensity in 6 cases (23.1\%) and hypo-isointensity in 20 cases (76.9\%), while non-TNBCs were T2-hyperintense in 2 cases (8.3\%) and hypo-isointense in 22 cases $(91.7 \%)$ $(p=0.301)$. Additional tumor features detectable on T2-weighted sequences, such as intralesional necrosis, resulted significantly associated with the TNBC subtype $(p=0.016)$ in our study population, while no association was found between TNBC and peritumoral edema $(p=0.880)$.

$13(50 \%)$ TNBCs and $5(20.8 \%)$ non-TNBCs were multifocal or multicentric $(p=0.064)$ and 16 $(61.5 \%)$ of group 1 (with TNBC) and $10(41.7 \%)$ of group 2 (with non-TNBC) had at least one axillary or internal mammary lymphadenopathy. No statistically significant association was found between the detection of loco-regional lymphadenopathies at MRI and TNBC subtype $(p=0.262)$ in 26 patients ( $52 \%$ of total population).

Further details about MRI features associated with TNBC and non-TNBC are shown in Table 1. 
Table 1. MRI features. Statistically significant $p$-values are bolded.

\begin{tabular}{|c|c|c|c|}
\hline & TNBC & Non-TNBC & $p$-Value \\
\hline Number of Patients & 26 & 24 & \\
\hline \multicolumn{4}{|l|}{ Tumor size } \\
\hline$\geq 2 \mathrm{~cm}$ & $15(57.7 \%)$ & $11(45.8 \%)$ & \multirow{2}{*}{0.308} \\
\hline$<2 \mathrm{~cm}$ & $11(42.3 \%)$ & $13(54.2 \%)$ & \\
\hline \multicolumn{4}{|l|}{ Enhancement } \\
\hline Mass & $24(92.3 \%)$ & $22(91.7 \%)$ & \multirow[t]{2}{*}{0.192} \\
\hline Non-mass & $2(7.7 \%)$ & $2(8.3 \%)$ & \\
\hline \multicolumn{4}{|l|}{ Shape (masses) } \\
\hline Round & $9(37.5 \%)$ & $3(13.6 \%)$ & \multirow{3}{*}{0.005} \\
\hline Oval & $5(20.8 \%)$ & 0 & \\
\hline Irregular & $10(41.7 \%)$ & $19(86.4 \%)$ & \\
\hline \multicolumn{4}{|l|}{ Margins (masses) } \\
\hline Circumscribed & $14(58.4 \%)$ & $2(9.1 \%)$ & \multirow[t]{2}{*}{0.001} \\
\hline Irregular/Spiculated & $10(41.6 \%)$ & $20(90.9 \%)$ & \\
\hline \multicolumn{4}{|l|}{ Rim enhancement (masses) } \\
\hline Yes & $18(75.0 \%)$ & $2(9.1 \%)$ & \multirow[t]{2}{*}{$<0.001$} \\
\hline No & $6(25.0 \%)$ & $20(90.9 \%)$ & \\
\hline \multicolumn{4}{|l|}{ T2-signal intensity } \\
\hline Hyperintensity & $6(23.1 \%)$ & $2(8.3 \%)$ & \multirow[t]{2}{*}{0.301} \\
\hline Isointensity/Hypointensity & $20(76.9 \%)$ & $22(91.7 \%)$ & \\
\hline \multicolumn{4}{|l|}{ Intralesional necrosis } \\
\hline Yes & $11(42.3 \%)$ & $2(8.3 \%)$ & \multirow[t]{2}{*}{0.016} \\
\hline No & $15(57.7 \%)$ & $22(91.7 \%)$ & \\
\hline \multicolumn{4}{|l|}{ Perilesional edema } \\
\hline Yes & $6(23.1 \%)$ & $5(20.8 \%)$ & \multirow[t]{2}{*}{0.88} \\
\hline No & $20(76.9 \%)$ & $19(79.2 \%)$ & \\
\hline \multicolumn{4}{|l|}{ Multifocality/Multicentricity } \\
\hline Yes & $13(50.0 \%)$ & $5(20.8 \%)$ & \multirow[t]{2}{*}{0.064} \\
\hline No & $13(50.0 \%)$ & $19(79.2 \%)$ & \\
\hline \multicolumn{4}{|l|}{ Abnormal lymph nodes } \\
\hline Yes & $16(61.5 \%)$ & $10(41.7 \%)$ & \multirow[t]{2}{*}{0.262} \\
\hline No & $10(38.5 \%)$ & $14(58.3 \%)$ & \\
\hline
\end{tabular}

The univariate analysis proved that not circumscribed margins are a negative predictor of TNBC (OR $=0.03$, CI 95\% $=0.01-0.17, p=0.0001)$, while rim enhancement and the presence of intralesional necrosis are positive predictors $(\mathrm{OR}=29.86$, CI 95\% $=5.53-161.35, p=0.0001$ and $\mathrm{OR}=8.10, \mathrm{CI} 95 \%=1.56-41.72, p=0.01$, respectively). The multivariate analysis confirmed that the presence of rim enhancement is independently associated with TNBC $(\mathrm{OR}=33.08, \mathrm{CI} 95 \%=1.59-687.55$, $p=0.02)$ while not circumscribed margins are not (OR 0.03, CI 95\% $=0.002-0.34, p=0.005)$ (see Table 2$)$. 
Table 2. Logistic regression analyses. Statistically significant $p$-values are bolded.

\begin{tabular}{|c|c|c|c|c|}
\hline & \multicolumn{2}{|c|}{ Univariate Analysis } & \multicolumn{2}{|c|}{ Multivariate Analysis } \\
\hline & OR (CI 95\%) * & $p$-Value & OR (CI 95\%) * & $p$-Value \\
\hline Tumor size $\geq 2 \mathrm{~cm}$ & $1.61(0.53-4.93)$ & 0.4 & - & - \\
\hline \multicolumn{5}{|l|}{ Enhancement } \\
\hline Mass & $1.10(0.14-8.42)$ & 0.93 & - & - \\
\hline Non-mass & $1.44(0.22-9.42)$ & 0.7 & & \\
\hline \multicolumn{5}{|l|}{ Shape (masses) } \\
\hline Round & $3.0(0.30-31.63)$ & 0.4 & 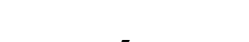 & _. \\
\hline Oval & Out of scale & 1 & & \\
\hline Irregular & $0.53(0.06-4-32)$ & 0.55 & & \\
\hline Irregular/Spiculated margins (masses) & $0.03(0.01-0.17)$ & $<0.001$ & $0.03(0.002-0.34)$ & 0.005 \\
\hline Rim enhancement (masses) & $29.86(5.53-161.35)$ & $<0.001$ & $33.08(1.59-687.55)$ & 0.02 \\
\hline \multicolumn{5}{|l|}{ T2-signal intensity } \\
\hline Hyperintensity & $0.22(0.04-1.24)$ & 0.09 & - & - \\
\hline Isointensity/Hypointensity & $1.20(0.12-11.0)$ & 0.89 & & \\
\hline Intralesional necrosis & $8.10(1.56-41.72)$ & 0.01 & $0.52(0.02-11.04)$ & 0.67 \\
\hline Perilesional edema & $1.14(0.30-4.37)$ & 0.85 & - & - \\
\hline
\end{tabular}

The mean ADC values were $1.04 \times 10^{-3} \mathrm{~mm}^{2} / \mathrm{s}(\mathrm{SD}=0.2)$ for TNBCs and $0.92 \times 10^{-3} \mathrm{~mm}^{2} / \mathrm{s}$ $(\mathrm{SD}=0.1)$ for non-TNBCs $(p=0.011)$.

\section{Discussion}

Triple-negative tumor is an aggressive subtype of breast cancer with peculiar features in terms of biology and response to therapy. As known, TNBC is highly chemosensitive and cannot benefit from endocrine or targeted therapy, unlike other subtypes of breast cancer. For this reason, NACT represents nowadays the treatment of choice in this group of tumors [2,5,25]. It is also well-known that TNBC has frequently benign-like features at conventional breast imaging (Figure 1) and that it presents specific associated features at MRI (Figure 2) more often than other subtypes of breast cancer. Moreover, a preliminary study has demonstrated that TNBC is prevalent among patients with marked background parenchymal enhancement [26]. Therefore, the aim of this study was to investigate MRI features of TNBC compared with non-TNBC, to possibly predict histopathological results on the basis of MRI biomarkers, considering that, as far as the authors know, there are few studies based on the comparison between MRI features of TNBC and non-TNBC and that the great majority of them were conducted at 1.5 T scanners and did not include functional techniques such as DWI [10,14,16-21].

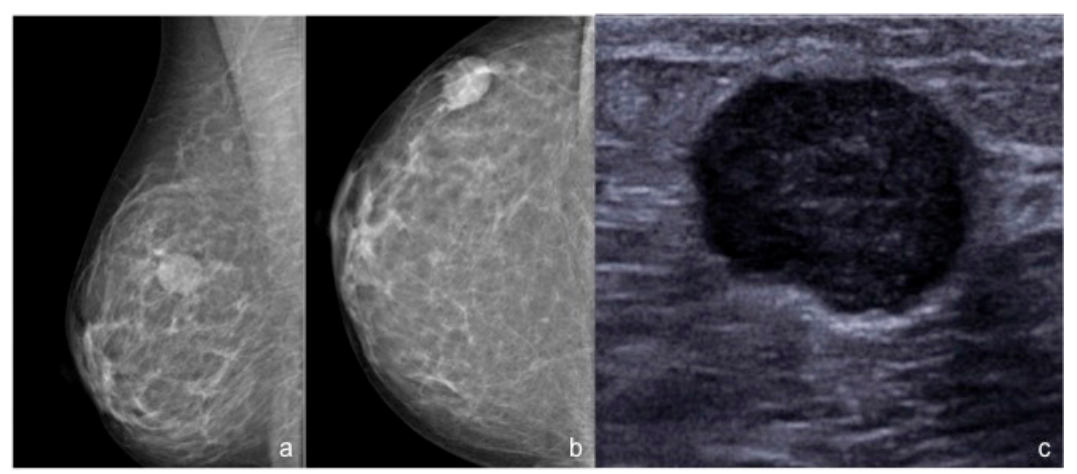

Figure 1. 55-year-old woman with a palpable nodule in the upper outer quadrant of the right breast. $(\mathbf{a}, \mathbf{b})$ Standard mammography of the right breast (ACR B) shows a corresponding round high-density mass, with circumscribed margins. (c) Targeted US scan detects a corresponding round hypoechoic mass with slightly microlobulated margins. The histopathological analysis after CNB revealed a TNBC. 


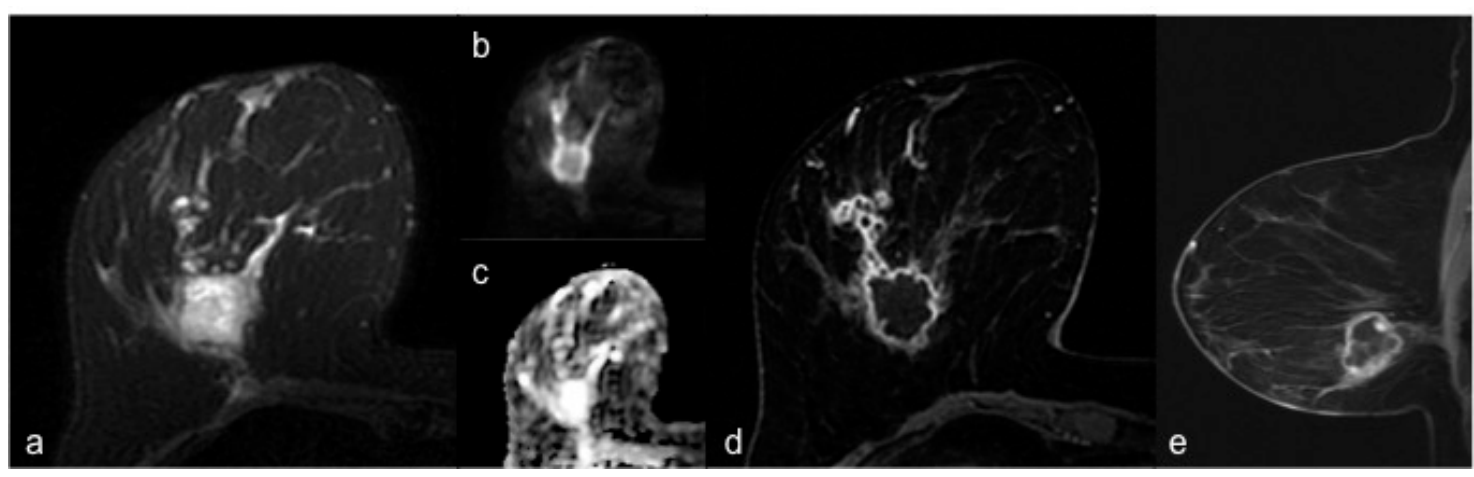

Figure 2. Breast MRI of a 53-year-old woman with TNBC of the right breast. (a) Axial fat-suppressed T2-weighted image shows a hyperintense round mass with irregular margins in the lower outer quadrant of the right breast. (b) Axial DWI image (b value $=1000 \mathrm{~s} / \mathrm{mm}^{2}$ ) shows peripheral high signal intensity and central hypointensity. The mass appears homogeneously hyperintense in the corresponding ADC map (c). (d) Axial and sagittal (e) post-contrast T1-weighted images show a corresponding irregular round mass with rim enhancement and some small foci of enhancement connected posteriorly by thin striae.

In our study, the majority of TNBCs appeared as mass enhancements characterized by circumscribed margins at MRI examination. Moreover, $58.3 \%$ of TNBCs in our sample were regular shaped masses (round or oval). These results confirm existing data in literature [10-12,14]. On the contrary, irregular shape was significantly more frequently associated with non-TNBC (Figure 3).

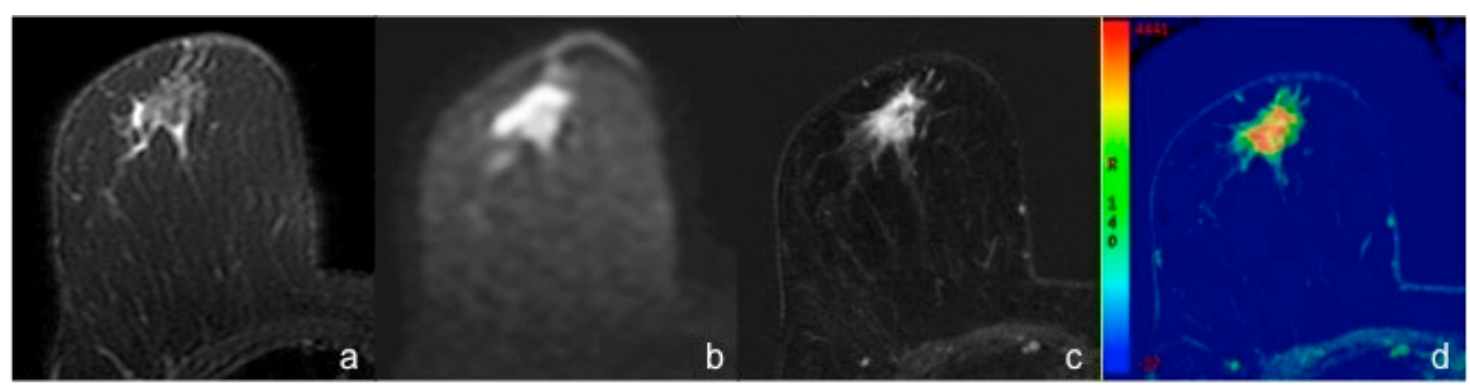

Figure 3. Breast MRI of a 57-year-old woman with IDC of the right breast (Luminal B). (a) Axial fat-suppressed T2-weighted image shows a hypointense irregular mass with spiculated margins and some hyperintense peripheric areas consistent with perilesional edema, in the retroareolar region. (b) Axial DWI image (b value $=1000 \mathrm{~s} / \mathrm{mm}^{2}$ ) shows the high signal intensity of the mass, corresponding to a restricted diffusion area. (c) Axial early post-contrast T1-weighted image and the corresponding perfusion color map (d) show a $16 \mathrm{~mm}$ irregular mass with spiculated margins and heterogeneous enhancement.

These features can be explained by the typical non-infiltrative growth pattern of TNBC, characterized by "pushing borders" [27], with good demarcated and "rolled-back" margins [28,29]. Considering the imaging and pathological features of these tumors, Yang et al. [30] suggested the existence of a more rapid pattern of carcinogenesis for TNBC, compared to other subtypes of breast cancers, that leads directly to invasive cancer, without major in situ components or precancerous stages. This theory could explain the lack of calcifications on standard mammography and the low incidence of ductal carcinoma in situ (DCIS) in TNBC. In this study $100 \%$ of TNBCs were pure invasive ductal carcinomas (IDC) without cases of associated DCIS; this result is higher than data in literature $(80-90 \%$ of TNBCs are IDC $[5,31])$, but it could be explained by the relative small number of the sample. Moreover the rapid growth of TNBC, that usually presents as an interval cancer [5], could be responsible for the absence of the desmoplastic reaction that is typically associated to breast cancer and is responsible for the infiltrating appearance [21,32]. 
Our study confirmed that rim enhancement is a positive predictor of TNBC subtype at histological examination, and that it is independently associated with TNBC. These results are consistent with what previously reported in literature $[10,12,17,33]$. In this study internal enhancement characteristics were classified as rim enhancement in $75 \%$ of TNBCs, compared to $80 \%$ reported by Uematsu et al. [33], $76 \%$ by Dogan et al. [12], $68 \%$ by Angelini et al. [17], and $57 \%$ by Sung et al. [10]. Rim enhancement on DCE-MRI is an established finding of malignant breast lesions, and it is known to be associated with increased angiogenesis and vascular endothelial growth factor expression and negative expression of estrogen and progesterone receptors [34,35]. Moreover, several research studies have shown that recurrence occurred more frequently in rim-enhancing TNBC [34,36,37].

The presence of intralesional necrosis was the other positive predictor of TNBC subtype in this study, in accordance with literature [16,33]. In this study only $23 \%$ of TNBCs showed high T2-signal intensity, compared to $25-84 \%$ reported in previous studies $[7,10,14,17,20,33,34]$; however $75 \%$ of the hyperintense tumors in both groups $(6 / 8)$ were TNBC. The reason behind this variability remains unclear, but it could be mainly explained by the fact that in the present study the evaluation of T2-signal intensity was based on the predominant signal intensity of each lesion; as a consequence, lesions with only small areas of T2-hyperintensity, possibly related to intralesional necrosis, were not classified as T2-hyperintense. Anyway it should be remembered that T2-hyperintensity is due to a combination of abundant cytoplasm, edematous stroma and necrosis $[17,33]$ and that histologic correlation was not investigated, except in one mentioned study [33].

Another breast tumor-associated feature detectable on T2-weighted sequences is peritumoral edema, which was demonstrated to correlate with biologically aggressive non-luminal breast cancers [38,39]. However, no association was found between TNBC and peritumoral edema in this study. This result can be explained by the larger tumor size of TNBCs included in those studies compared to ours and by the small number of patients.

TNBC tumor size is usually larger than non-TNBC on MRI at diagnosis [27]. In this study, TNBC were larger than non-TNBC on average, even if no statistical association was found between tumor size and TNBC subtype. This result is presumably explained once again by the relatively small size of our population, that was probably insufficient to detect a statistically significant difference. As a matter of fact, about $60 \%$ of TNBCs considered for this study measured $\geq 2 \mathrm{~cm}$ and our results are similar to previous data in literature $(63 \%$ [21]).

For what concerns functional techniques, the mean $\mathrm{ADC}$ values were significantly higher for TNBCs than for non-TNBCs; even if it was not possible to establish a cut-off value, given the small study population, our data confirm the few pieces of evidence reported in previous studies [14,15]. Such difference in ADC values was suggested to be due to the presence of necrosis, that determines a fall in tumor cellularity with consequent increased diffusion [28].

Our study demonstrated that certain MRI features are significantly associated with TNBC on a $3 \mathrm{~T}$ scanner, such as circumscribed margins, rim enhancement and the presence of intralesional necrosis. On the contrary, irregular mass shape and not circumscribed margins, resulted more frequently associated with non-TNBC. Regarding functional imaging, the mean ADC values were significantly higher for TNBCs than for non-TNBCs. Nevertheless, we have several limitations. First of all, it is a monocentric, retrospective analysis, including a relatively small number of patients; therefore, results need to be further validated in larger population prospective studies. However, the number of patients included in other similar studies was not much bigger or even lower in some cases $[7,12,13,16,17,20]$. Second, the molecular subtypes of breast cancer were determined using immunohistochemical surrogates that lack in standardization, compared to gene profiling, even if they have shown similar clinical significance and are nowadays routinely used [40]. Finally, this study did not include a long-term evaluation of possible prognostic implications of MRI features associated with TNBC.

In the last decade researchers have demonstrated that different human cancer phenotypes show specific imaging texture features [41] and several authors have suggested that radiogenomic markers 
are able to distinguish among molecular subtypes of breast cancer [42-46]. Our objective for the future is to implement techniques of radiogenomic analyis in our research, to validate these promising results.

\section{Conclusions}

Our study suggests that TNBC is associated with specific features at MP-MRI that can be predictors of immunohistochemical and pathological results, with a consequent prognostic value. Further studies are needed to evaluate the possible impact of these findings on patient management in clinical practice.

Author Contributions: Conceptualization G.M., F.G., E.C. and F.P.; Data Curation G.M. and E.C.; Investigation E.C., V.R. and E.K.; Methodology F.G., E.C., G.D. and F.P.; Supervision F.G., G.D. and F.P.; Validation G.D. and F.P.; Writing G.M. All authors have read and agreed to the published version of the manuscript.

Funding: This research received no external funding.

Conflicts of Interest: The authors declare no conflict of interest.

\section{References}

1. Coates, A.S.; Winer, E.P.; Goldhirsch, A.; Gelber, R.D.; Gnant, M.; Piccart-Gebhart, M.; Thürlimann, B.; Senn, H.J.; Panel Members. Tailoring therapies-Improving the management of early breast cancer: St Gallen International Expert Consensus on the Primary Therapy of Early Breast Cancer 2015. Ann. Oncol. 2015, 26, 1533-1546. [CrossRef] [PubMed]

2. Harbeck, N.; Gnant, M. Breast cancer. Lancet 2017, 389, 1134-1150. [CrossRef]

3. Vuong, D.; Simpson, P.T.; Green, B.; Cummings, M.C.; Lakhani, S.R. Molecular classification of breast cancer. Virchows Arch. 2014, 465, 1-14. [CrossRef] [PubMed]

4. Goldhirsch, A.; Winer, E.P.; Coates, A.S.; Gelber, R.D.; Piccart-Gebhart, M.; Thürlimann, B.; Senn, H.J.; Panel Members. Personalizing the treatment of women with early breast cancer: Highlights of the St Gallen International Expert Consensus on the Primary Therapy of Early Breast Cancer 2013. Ann. Oncol. 2013, 24, 2206-2223. [CrossRef] [PubMed]

5. Kumar, P.; Aggarwal, R. An overview of triple-negative breast cancer. Arch. Gynecol. Obstet. 2016, 293, 247-269. [CrossRef] [PubMed]

6. Atchley, D.P.; Albarracin, C.T.; Lopez, A.; Valero, V.; Amos, C.I.; Gonzalez-Angulo, A.M.; Hortobagyi, G.N.; Arun, B.K. Clinical and pathologic characteristics of patients with BRCA-positive and BRCA-negative breast cancer. J. Clin. Oncol. 2008, 26, 4282-4288. [CrossRef]

7. Boisserie-Lacroix, M.; Mac Grogan, G.; Debled, M.; Ferron, S.; Asad-Syed, M.; Brouste, V.; Mathoulin-Pelissier, S.; Hurtevent-Labrot, G. Radiological features of triple-negative breast cancers (73 cases). Diagn. Interv. Imaging 2012, 93, 183-190. [CrossRef]

8. Dogan, B.E.; Turnbull, L.W. Imaging of triple-negative breast cancer. Ann. Oncol. 2012, 23 (Suppl. S66), 23-29. [CrossRef]

9. Tian, L.; Wang, L.; Qin, Y.; Cai, J. Systematic review and meta-analysis of the malignant ultrasound features of triple negative breast cancer. J. Ultrasound Med. 2020, 39, 2013-2025. [CrossRef]

10. Sung, J.S.; Jochelson, M.S.; Brennan, S.; Joo, S.; Wen, Y.H.; Moskowitz, C.; Zheng, J.; Dershaw, D.D.; Morris, E.A. MR imaging features of triple-negative breast cancers. Breast J. 2013, 19, 643-649. [CrossRef]

11. Uematsu, T. MR imaging of triple-negative breast cancer. Breast Cancer 2011, 18, 161-164. [CrossRef] [PubMed]

12. Dogan, B.E.; Gonzalez-Angulo, A.M.; Gilcrease, M.; Dryden, M.J.; Yang, W.T. Multimodality imaging of triple receptor-negative tumors with mammography, ultrasound, and MRI. AJR Am. J. Roentgenol. 2010, 194, 1160-1166. [CrossRef] [PubMed]

13. Chen, J.H.; Agrawal, G.; Feig, B.; Baek, H.M.; Carpenter, P.M.; Mehta, R.S.; Nalcioglu, O.; Su, M.Y. Triple-negative breast cancer: MRI features in 29 patients. Ann. Oncol. 2007, 18, 2042-2043. [CrossRef] [PubMed]

14. Youk, J.H.; Son, E.J.; Chung, J.; Kim, J.A.; Kim, E.K. Triple-negative invasive breast cancer on dynamic contrast-enhanced and diffusion-weighted MR imaging: Comparison with other breast cancer subtypes. Eur. Radiol. 2012, 22, 1724-1734. [CrossRef] 
15. Martincich, L.; Deantoni, V.; Bertotto, I.; Redana, S.; Kubatzki, F.; Sarotto, I.; Rossi, V.; Liotti, M.; Ponzone, R.; Aglietta, M.; et al. Correlations between diffusion-weighted imaging and breast cancer biomarkers. Eur. Radiol. 2012, 22, 1519-1528. [CrossRef] [PubMed]

16. Gigli, S.; Amabile, M.I.; David, E.; De Luca, A.; Grippo, C.; Manganaro, L.; Monti, M.; Ballesio, L. Morphological and semiquantitative kinetic analysis on dynamic contrast enhanced MRI in triple negative breast cancer Patients. Acad. Radiol. 2019, 26, 620-625. [CrossRef]

17. Angelini, G.; Marini, C.; Iacconi, C.; Mazzotta, D.; Moretti, M.; Picano, E.; Morganti, R. Magnetic resonance (MR) features in triple negative breast cancer (TNBC) vs receptor positive cancer (nTNBC). Clin. Imaging 2018, 49, 12-16. [CrossRef]

18. Vilar, L.N.; Alandete Germán, S.P.; Medina García, R.; Blanc García, E.; Camarasa Lillo, N.; Vilar Samper, J. MR Imaging findings in molecular subtypes of breast cancer according to BIRADS System. Breast J. 2017, 23, 421-428. [CrossRef]

19. Bae, M.S.; Seo, M.; Kim, K.G.; Park, I.A.; Moon, W.K. Quantitative MRI morphology of invasive breast cancer: Correlation with immunohistochemical biomarkers and subtypes. Acta Radiol. 2015, 56, 269-275. [CrossRef]

20. Boisserie-Lacroix, M.; Macgrogan, G.; Debled, M.; Ferron, S.; Asad-Syed, M.; McKelvie-Sebileau, P.; Mathoulin-Pélissier, S.; Brouste, V.; Hurtevent-Labrot, G. Triple-negative breast cancers: Associations between imaging and pathological findings for triple-negative tumors compared with hormone receptor-positive/human epidermal growth factor receptor-2-negative breast cancers. Oncologist 2013, 18, 802-811. [CrossRef]

21. Choi, J.J.; Kim, S.H.; Cha, E.S.; Kang, B.J.; Lee, J.H.; Lee, S.Y.; Jeong, S.H.; Yim, H.W.; Song, B.J. MRI findings of triple negative breast cancer: A comparison with non-triple negative breast cancer. JKSMRM J. Korean Soc. Magn. Reson. Med. 2010, 14, 95-102. [CrossRef]

22. Mann, R.M.; Balleyguier, C.; Baltzer, P.A.; Bick, U.; Colin, C.; Cornford, E.; Evans, A.; Fallenberg, E.; Forrai, G.; Fuchsjäger, M.H.; et al. European Society of Breast Imaging (EUSOBI), with language review by Europa Donna-The European Breast Cancer Coalition. Breast MRI: EUSOBI recommendations for women's information. Eur. Radiol. 2015, 25, 3669-3678. [CrossRef] [PubMed]

23. Morris, E.A.; Comstock, C.E.; Lee, C.H. ACR BI-RADS Magnetic Resonance Imaging. In ACR BI-RADS Atlas, Breast Imaging Reporting and Data System, 5th ed.; American College of Radiology: Reston, VA, USA, 2013.

24. Wolff, A.C.; Hammond, M.E.; Hicks, D.G.; Dowsett, M.; McShane, L.M.; Allison, K.H.; Allred, D.C.; Bartlett, J.M.; Bilous, M.; Fitzgibbons, P.; et al. Recommendations for human epidermal growth factor receptor 2 testing in breast cancer: American Society of Clinical Oncology/College of American Pathologists clinical practice guideline update. J. Clin. Oncol. 2013, 31, 3997-4013. [CrossRef] [PubMed]

25. Cardoso, F.; Kyriakides, S.; Ohno, S.; Penault-Llorca, F.; Poortmans, P.; Rubio, I.T.; Zackrisson, S.; Senkus, E.; ESMO Guidelines Committee. Early breast cancer: ESMO Clinical Practice Guidelines for diagnosis, treatment and follow-up. Ann. Oncol. 2019, 30, 1194-1220. [CrossRef] [PubMed]

26. Dilorenzo, G.; Telegrafo, M.; La Forgia, D.; Stabile Ianora, A.A.; Moschetta, M. Breast MRI background parenchymal enhancement as an imaging bridge to molecular cancer sub-type. Eur. J. Radiol. 2019, 113, 148-152. [CrossRef]

27. Li, J.; Han, X. Research and progress in magnetic resonance imaging of triple-negative breast cancer. Magn. Reson. Imaging 2014, 32, 392-396. [CrossRef]

28. Alili, C.; Pages, E.; Curros Doyon, F.; Perrochia, H.; Millet, I.; Taourel, P. Correlation between MR imaging-Prognosis factors and molecular classification of breast cancers. Diagn. Interv. Imaging 2014, 95, 235-242. [CrossRef]

29. Wang, D.; Zhu, K.; Tian, J.; Li, Z.; Du, G.; Guo, Q.; Wu, T.; Li, J. Clinicopathological and ultrasonic features of triple-negative breast cancers: A comparison with hormone receptor-positive/human epidermal growth factor receptor-2-negative breast cancers. Ultrasound Med. Biol. 2018, 44, 1124-1132. [CrossRef]

30. Yang, W.T.; Dryden, M.; Broglio, K.; Gilcrease, M.; Dawood, S.; Dempsey, P.J.; Valero, V.; Hortobagyi, G.; Atchley, D.; Arun, B. Mammographic features of triple receptor-negative primary breast cancers in young premenopausal women. Breast Cancer Res. Treat. 2008, 111, 405-410. [CrossRef]

31. Yao, H.; He, G.; Yan, S.; Chen, C.; Song, L.; Rosol, T.J.; Deng, X. Triple-negative breast cancer: Is there a treatment on the horizon? Oncotarget 2017, 8, 1913-1924. [CrossRef] 
32. Shin, H.J.; Kim, H.H.; Huh, M.O.; Kim, M.J.; Yi, A.; Kim, H.; Son, B.H.; Ahn, S.H. Correlation between mammographic and sonographic findings and prognostic factors in patients with node-negative invasive breast cancer. Br. J. Radiol. 2011, 84, 19-30. [CrossRef]

33. Uematsu, T.; Kasami, M.; Yuen, S. Triple-negative breast cancer: Correlation between MR imaging and pathologic findings. Radiology 2009, 250, 638-647. [CrossRef] [PubMed]

34. Lee, Y.J.; Youn, I.K.; Kim, S.H.; Kang, B.J.; Park, W.C.; Lee, A. Triple-negative breast cancer: Pretreatment magnetic resonance imaging features and clinicopathological factors associated with recurrence. Magn. Reson. Imaging 2020, 66, 36-41. [CrossRef] [PubMed]

35. Agrawal, G.; Su, M.Y.; Nalcioglu, O.; Feig, S.A.; Chen, J.H. Significance of breast lesion descriptors in the ACR BI-RADS MRI lexicon. Cancer 2009, 115, 1363-1380. [CrossRef] [PubMed]

36. Schmitz, A.M.; Loo, C.E.; Wesseling, J.; Pijnappel, R.M.; Gilhuijs, K.G. Association between rim enhancement of breast cancer on dynamic contrast-enhanced MRI and patient outcome: Impact of subtype. Breast Cancer Res. Treat. 2014, 148, 541-551. [CrossRef]

37. Chang, Y.W.; Kwon, K.H.; Choi, D.L.; Lee, D.W.; Lee, M.H.; Lee, H.K.; Yang, S.B.; Kim, Y.; Seo, D.Y. Magnetic resonance imaging of breast cancer and correlation with prognostic factors. Acta Radiol. 2009, 50, 990-998. [CrossRef]

38. Panzironi, G.; Moffa, G.; Galati, F.; Marzocca, F.; Rizzo, V.; Pediconi, F. Peritumoral edema as a biomarker of the aggressiveness of breast cancer: Results of a retrospective study on a 3 T scanner. Breast Cancer Res. Treat. 2020, 181, 53-60. [CrossRef]

39. Costantini, M.; Belli, P.; Distefano, D.; Bufi, E.; Matteo, M.D.; Rinaldi, P.; Giuliani, M.; Petrone, G.; Magno, S.; Bonomo, L. Magnetic resonance imaging features in triple-negative breast cancer: Comparison with luminal and HER2-overexpressing tumors. Clin. Breast Cancer 2012, 12, 331-339. [CrossRef]

40. Tang, P.; Tse, G.M. Immunohistochemical surrogates for molecular classification of breast carcinoma: A 2015 update. Arch. Pathol. Lab. Med. 2016, 140, 806-814. [CrossRef]

41. Aerts, H.J.; Velazquez, E.R.; Leijenaar, R.T.; Parmar, C.; Grossmann, P.; Carvalho, S.; Bussink, J.; Monshouwer, R.; Haibe-Kains, B.; Rietveld, D.; et al. Decoding tumour phenotype by noninvasive imaging using a quantitative radiomics approach. Nat. Commun. 2014, 5, 4006. [CrossRef]

42. Sun, X.; He, B.; Luo, X.; Li, Y.; Cao, J.; Wang, J.; Dong, J.; Sun, X.; Zhang, G. Preliminary study on molecular subtypes of breast cancer based on magnetic resonance imaging texture analysis. J. Comput. Assist. Tomogr. 2018, 42, 531-535. [CrossRef] [PubMed]

43. Saha, A.; Harowicz, M.R.; Grimm, L.J.; Kim, C.E.; Ghate, S.V.; Walsh, R.; Mazurowski, M.A. A machine learning approach to radiogenomics of breast cancer: A study of 922 subjects and 529 DCE-MRI features. Br. J. Cancer 2018, 119, 508-516. [CrossRef] [PubMed]

44. Grimm, L.J.; Zhang, J.; Baker, J.A.; Soo, M.S.; Johnson, K.S.; Mazurowski, M.A. Relationships between MRI Breast Imaging-Reporting and Data System (BI-RADS) lexicon descriptors and breast cancer molecular subtypes: Internal enhancement is associated with luminal B subtype. Breast J. 2017, 23, 579-582. [CrossRef] [PubMed]

45. Fan, M.; Li, H.; Wang, S.; Zheng, B.; Zhang, J.; Li, L. Radiomic analysis reveals DCE-MRI features for prediction of molecular subtypes of breast cancer. PLoS ONE 2017, 12, e0171683. [CrossRef]

46. Li, H.; Zhu, Y.; Burnside, E.S.; Huang, E.; Drukker, K.; Hoadley, K.A.; Fan, C.; Conzen, S.D.; Zuley, M.; Net, J.M.; et al. Quantitative MRI radiomics in the prediction of molecular classifications of breast cancer subtypes in the TCGA/TCIA data set. NPJ Breast Cancer 2016, 2, 1-10. [CrossRef]

Publisher's Note: MDPI stays neutral with regard to jurisdictional claims in published maps and institutional affiliations.

(C) 2020 by the authors. Licensee MDPI, Basel, Switzerland. This article is an open access article distributed under the terms and conditions of the Creative Commons Attribution (CC BY) license (http://creativecommons.org/licenses/by/4.0/). 